\title{
Hypothesis on the Forensic Recognition of Cases "Brought in Dead" and Others "Brought in Dying"
}

\author{
Deirdre Twomey and Wilson I B Onuigbo* \\ Department of Pathology, Medical Foundation \& Clinic, Nigeria \\ *Corresponding author: Wilson I B Onuigbo, Department of Pathology, Medical Foundation \& Clinic, 8 Nsukka Lane, Enugu-410000, Nigeria

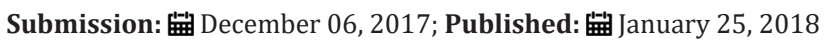

\begin{abstract}
The best known forensic cases are those "Brought in Dead," i.e., BID. Perhaps, there is need to appreciate other cases marked by reaching the hospital but dying there, i.e., "Brought in Dying." Examples of the latter need both recognition and documentation. This was achieved in the present paper concerning members of the Igbo Ethnic Group who are domiciled in South Eastern Nigeria. It is hypothesized that there should be wider knowledge of the phenomenon of "Brought in Dying.
\end{abstract}

Keywords: Death; "Brought in Dead”; “Brought in Dying”; Forensic Pathology; Hypothesis; Time Factor

\section{Introduction}

In a carefully documented forensic paper from Finland [1], a group of cases consisted of those "brought in dead" and were classified as BID. In sharp contrast, there is another class, namely, those who may be "brought in dying." The latter cases deserve recognition from the author's experience among his own Ethnic Group, the Ibos or Igbos [2]. Incidentally, this approach was facilitated in a Regional Pathology Laboratory, at Enugu, in keeping with the advice of a Birmingham (UK) group to the effect that a histopathology data pool facilitates epidemiological analysis [3].

\section{Investigation}

Dating back to the end of the Nigerian Civil War in 1970, the Eastern Region Government, with its capital at Enugu, established a Regional Pathology Laboratory of which the author became the pioneer pathologist. Having insisted on receiving specimens provided that they were accompanied by good clinical details, it became possible to amass data over the years [4]. Moreover, the data were also kept personally, thus facilitating manual analysis with special reference to the patients who were "brought in dying."

\section{Case Reports}

1. A 25-year-old man was brought to the Joint Hospital, Ikom. Unfortunately, he was brought in as he was vomiting blood. He died on admission. Following autopsy, several specimens were obtained and sent to the author. My diagnosis was clear, namely, "The significant findings are in the lungs which show a range of tuberculous lesions, ranging from the fibrocaseous, through the cavitating to the tuberculous bronchopneumonia."
2. A woman aged 20 years was referred from Toronto Hospital, Onitsha, to the Enugu Specialist Hospital. On admission, she was deeply unconscious. She was placed immediately on Inj Lasix and Inj Reserpine. Oxygen therapy was administered and foamy substances aspirated through the nostrils. Not long after, the patient began to gasp for breath but soon died. At necropsy, both kidneys were small. Microscopy revealed a few normal glomeruli, the vast majority being sclerotic. The parenchyma was atrophic while the tubules were full of eosiophilic casts. Uremia was diagnosed.

3. A woman aged 29 years attended the Out Patient at the Enugu Specialist Hospital in the afternoon with a month's history of weakness, anorexia, abdominal distension and edema. There was triple rhythm. There was anemia with tropical splenomegaly. She collapsed on the way to the Ward and could not be resuscitated. Autopsy disclosed mainly tropical splenomegaly.

4. The patient attended the Enugu Specialist Hospital in an unconscious state with profuse hematemesis which continued even when he was brought into the Ward. On arrival, he was deeply unconscious with profuse outpouring of blood through the mouth and nose. He was gasping. Active resuscitation proved unavailing. At autopsy, the stomach was greatly dilated and distended with blood. There was mucosal sloughing in parallel as well as ridges of hemorrhagic surfaces.

\section{Discussion}

The first case stands out because it is likely that some epistaxis of a smaller extent must have manifested. In other words, health education in the community would have saved the situation [5]. 
The second patient died of renal disease. Canadian authors maintained that sudden cardiac death occurs in chronic kidney disease and discussed its epidemiology and prevention [6]. From Brazil, a whiff of hope was presented in this adverse disease [7]. Incidentally, different dimensions of this illness were discussed in USA [8], Australia [9], and Spain [10].

The third patient was found to be suffering from splenomegaly. A recent USA report concerned a 21-year-old man whose 630 grams spleen was rupture [11]. Operation was the saving grace.

Fourthly, there was sudden gastrointestinal death as was reported from India [12]. In 49-yeer-old Japanese [13], death from gastric rupture had occurred in a public lavatory. Finally, let me add the lesson taught by my co-author, an Irish Missionary doctor, Twomey [14], seeing that she worked assiduously in the Igbo hinterland. As she put it, women should be aware of the danger of burst tubal pregnancy. In particular, if a woman misses her period and feels faint in association with lower abdominal pain, she should rush to a hospital for treatment instead of being brought dead to it! In other words, the patient would have undergone curative salpingectomy in good time rather than being brought in dying! Yes! She had encountered sorrowful cases!

\section{References}

1. Severi L (1987) On the close connection between forensic medicine and pathology-A recollection. Med Sci Law 27(1): 61-62.

2. Basden GT (1966) Niger Ibos. Cass, London.

3. Macartney JC, Rollaston TP, Codling BW (1980) Use of a histopathology data pool for epidemiological analysis. J Clin Pathol 33: 351-353.
4. Onuigbo WIB (1980) Studies on the geographical pathology of the Igbos of Nigeria. MD Thesis, Glasgow University, UK.

5. Gopu GS, Rao VB, Vadivet J (2012) Impact of health education on the knowledge of tuberculosis among sputum-positive pulmonary TB patients and their care-givers. Nurs J India 103(4): 160-162.

6. Shamseddin MK, Parfrey PS (2011) Sudden cardiac death in chronic kidney disease: Epidemiology and prevention. Nat Rev Nephrol 7(3): 145-154.

7. Mion D (2016) Chronic kidney disease and risk factors responsible for sudden cardiac death: A whiff of hope? Kidney Res Clin Pract 31(1): 3-9.

8. Pun PH, Smarz TR, Honeycutt EF, Shaw LK, Al-Khatib SM, et al. (2009) Chronic kidney disease is associated with increased risk of sudden cardiac death among patients with coronary artery disease. Kidney Intl 76(6): 652-658.

9. Wong MCG, Kalman JM, Pedagogos E, Toussaint N, Vohra JK, et al. (2015) Bradycardia and asystole is the predominant mechanism of sudden cardiac death in patients with chronic kidney disease. J Am Coll Cardiol 65(12): 1263-1265.

10. Caravaca F, Chavez E, Alvarado R, García-Pino G, Luna E (2016) Sudden cardiac death in non-dialysis chronic kidney disease patients. Nefrologia 36: 404-409.

11. Shiber J, Fontane E, Prisk D (2014) A traumatic splenic rupture: Dreaded complication of splenomegaly. Trop Med Surg 2: 162.

12. Hugar BS, Harish S, Girishchandra YP, Jayanth SH (2014) Study of sudden gastrointestinal deaths: An autopsy study. Med Sci Law 54(2): 63-67.

13. Ishikawa T, Miyaishi S, Yamamoto Y, Yoshitome K, Inagaki S, et al. (2003) Sudden unexpected death due to rupture of the stomach. Leg Med 5(1): 60-64.

14. Twomey D (1994) Awareness of ectopic pregnancy. Nig J Surg Sci 4: 48. 